\title{
BETWEEN SUSPICION AND LOVE
}

Reality, Postcritique,

and Euro-American Modernization

(An Introduction to the Debate)

He told us, with the years you will come To love the world.

And we sat there with our souls in our laps And comforted them.

Dorothea Tanning, "Graduation" (2004)

Anyone who attends academic talks has learned to expect the inevitable question: "But what about power?" Perhaps it is time to start asking different questions: "But what about love?"

Rita Felski, The Limits of Critique (2015)

- or some time scholars in literary studies have felt the need - to ask anew about the central activity of the field: reading. More than a decade ago, the debate on "surface reading" or "just reading" inaugurated a reassessment of critical practice (Marcus 2007; Marcus and Best 2009). ${ }^{1}$ The phrase championed neither a return to literature as a kind of hortus conclusus sheltered from society and history, nor the idea of criticism reduced to isolated exegesis. Rather, it called for heightened attention to the details of the text. The reassessment continues today under the name of postcritique. Interestingly, the term

1. The phrase "just reading" is used by Sharon Marcus in Between Women: Friendship, Desire, and Marriage in Victorian England (Marcus 2007). 
One World

The Americas

Everywhere

is usually associated with the search for a new critical method in the humanities. ${ }^{2}$ Appreciating the significance of the search for fresh perspectives, it is however worth the while to shift the focus from the objective itself to the agency of the critic. The reflections presented in this text are meant to map out the dominant contexts, in which the prefix "post" chiefly occurs in order to open up possible vistas for a more indepth study of the role each of us may play in the epistemic transformation postulated, or awaited, by the proponents of postcritique today.

Acknowledging the diversity of critical voices in the field, it is perhaps not without reason to organize these reflections around Rita Felski's important neutralization of the "negativity," semantically inscribed into the term "critique." In her view, the essence of critique does not reside in acts leveled against the positions adopted by the proponents of particular artistic or theoretical perspectives on reality: conversely, it is founded upon acts of love. In her understanding, an act of critique is tantamount to an act of emancipation from suspicion to love-which the epigraphs to this essay so eloquently emphasize. Felski's postulate of critique-as-love provides us with an opportunity to re-consider the agency of the critic and its metamorphoses over time. Paradoxically, the poststructuralist turn, which (apparently) liberated the all-too-rigid hermeneutics of the periods preceeding it from its (structuralist) limitations, unexpectedly transformed the critic into a misguided reader whose senses, dulled with ideologically tinged "critical instrumentarium," have made him or her read the text through what is absent, and hear in it what has never been uttered.

Postcritique is a nuanced and multifaceted phenomenon. The contributors of the groundbreaking collection titled Critique and Postcritique, to give an impactful example, represent a complex set of legacies and methods. They advocate a turn

2. See Heather Love's project of "meticulous flat description" or other attempts, like Franco Moretti's "distant reading," which rely on data mining and cognitive science to confer scientific legitimacy and universal value to the interpretation of texts (Love 2010; Love 2013). Further core readings on description include Description Across Disciplines, special issue of Representations (2016), edited by Sharon Marcus, Heather Love and Stephen Best. 
that cannot be reduced to any simple, or simplistic, reaction to poststructuralism. Likewise, poststructuralism, that they move away from, cannot be reduced to a set of critical practices ancilliary to ideological purposes. Rather, these scholars' aim is to revitalize criticism poised at the productive confluence of aesthetics and politics. Yet, there is a sense in which postcritique names the waning of critique understood as inseparable from the narrative of local modernization, or, for the lack of a better phrasing, the western post-Enlightenment paradigm. This understanding of critique has consisted in the selective, mutual incorporation of European schools and the American tradition, too often in a linear manner. This might be the reason why what we hear as the disaffection for deconstructive gestures might be comprehended as a way of working through the loss of a local transatlantic past.

The term postcritique, therefore, affords a particular version of the "narrative of critique." When looked at from the outside of the "common," allegedly "western," narrative-for instance, through the lens of the so-called Italian theory, as exemplified by Roberto Esposito (and Croce, Gentile, and Gramsci before him) -the linear narrative proves untenable. Rather than arguing for the "post-," the proponents of "Italian theory" revert back to occlusions. In this perspective, the linear assimilation of schools and national intellectual traditions proves illusory. As a consequence, the ongoing critique represented by the "third-wave" of theory (Italian Theory), poses the problem of a latent thought, a thought that has not been contained within the methodologies born out of the linguistic turn. Such thought, unaccounted for, may be argued to be attuned to the dynamics of globalization: it is marked with a different sense of time, an with a pietas toward the past.

Although these reflections do not aspire to being conclusive, they are intended to offer a point of departure for further, perhaps more detailed, translocal studies bridging the two poles of the contemporary western thought across the Atlantic. To attain this goal, we should probably begin with exploring the question of what has brought on this change in the conception of what the critic is? 
Imagining different ways of reading, proponents of postcritique, such as Sharon Marcus and Stephen Best, champion a critical practice that will not construe "presence as absence and affirmation as negation" (Marcus 2007 qtd. in Marcus and Best 2009: 12). They question a critical practice that, at least in part, is the outcome of the excesses of poststructuralism, especially when it places the critic in competition with the text and endows the former with a greater freedom vis-à-vis the latter (Marcus and Best 2009: 18). It would of course be wrong to reduce poststructuralism to these excesses. In the Anglophone world, the term "poststructuralism," often refers to the displacement and relocation of French philosophy and criticism (from Roland Barthes's semiology to French feminisms to deconstruction) to the US. It names less a movement and more a cluster of authors who "were read and classified or compartmentalized" (Dillet 2017: 517) and, together, have facilitated the dialogue between different branches of knowledge, including psychoanalysis and Marxism. Like all labels, poststructuralism seems a rather inadequate name for a multiplicity of developments. Nevertheless, it can be argued that the principal effect of the departure from the former methodological perspectives on literary studies has been the recognition of the autonomy of the critic. Admittedly, to some scholars, this autonomy now appears as an emblem of the theoretical and politi-

One World The Americas Everywhere cal excesses that have encouraged "opportunist uses of texts from the past, primarily fueled by ideological or deconstructive purposes" (Collini 2015). Postcritique, however, is neither tantamount to the rejection of poststructuralism nor to its reduction to an opportunistic manipulation of texts. While it does take issue with symptomatic reading, that is to say, with reading that is motivated by the aim of unveiling the repressed meaning(s) of the text, it, as this analysis further demonstrates, also retains the propinquity to Marxism and psychoanalysis in its practice of interpretation (Marcus and Best 2009: 19). Postcritique wishes for the liberation of the literary critic from the burden of repressed meaning, but it nonetheless points out that the strategies imputed to poststructuralism (debunking and deconstructing binaries) 
reach further back into the past and thereby amount to the larger question of reality.

In the light of "Italian Theory," after Marx, it is strange to think of reality in empirical terms. Change comes to inhere to the concept of reality: the task of thinking about reality is "restituting living substance to the real" (Esposito 2020: 94). ${ }^{3}$ Psychoanalysis has joined Marxism and played an important role in the restitution process, since its central interest lies in "the coming to being of the new that was not there and that becomes real" (Lacan 2013: 136). ${ }^{4}$ But the question arises: how can reality contain the exigency of its own transformation? Those who perceive the exigency do not necessarily want a revolt against reality. Once reality is understood as praxis, the thought related to it is "objectively inclined to change it" (Esposito 2020: 194). The metamorphosis of the critic that brought about the exigency of postcritique may be understood as the legacy of the question of reality.

Marxism and psychoanalysis join forces to show that change is not an addition to knowledge, but that knowledge is synonymous with change. Language takes on a preeminent role in the task, to the extent that the entire arch of post-Saussurean modernity is dominated by the idea that experience is mediated by language. Poststructuralism, in this sense, is an iteration of the former vision of the world, yet, warped by the experience of the two World Wars, and mistrustful of the idea of "progress." In literary studies, it translates into a marked attention to resistance, struggle, difference, to the limits of knowledge and to the undoing of oppositions and binaries, ${ }^{5}$ with criticism attempting to renegotiate the "proper" distance between the critic and the text.

The idea that "experience has a transcendentally linguistic character" (Esposito 2016: 161) is central to the 20 ${ }^{\text {th }}$ century philosophical reflection (one thinks of Martin Heidegger's idea that language is the dwelling of man as combined with his concept of Sorge), coin-

3. For Esposito, this interrogation of reality reaches back to include $\mathrm{Ma}$ chiavelli (Esposito 2020: 193-207).

4. I am drawing on the Italian text of Lacan's "Discorso di Roma" (Lacan 2013:133-164), the stenographic transcript of the speech delivered by Lacan in Rome, 26 September 1953, that introduced "The Function and Field of Language in Psychoanalysis" (Lacan 1977: 30-113). My translation.

5. See Williams (2005); Bertens (2007). 
ciding with the belief that no "truth" exists that is not mediated by human conceptual systems, extends to literary studies as well (Fleissner 2017: 103). The theme of language and its inadequacy bridges the distance between (broadly understood) philosophy and literature. Especially with the rise of Theory, it brings into the foreground the question of the zone of contact between two neighboring fields: philosophical and literary criticism (in all senses of the terms involved). ${ }^{6}$

\section{CRAVING FOR OBJECTIVITY}

In this context, Jennifer Fleissner lists three major departures from the pre-poststructuralist past. First, the tendency now is to start from the assumption that there is a cluster of objective facts that the critic should discern; second, the task of the critic is seen as that of grasping these objective facts in as accurate a manner as possible; third, the critic's subjectivity should be advantageously enlisted in the process of discerning objective facts (2017: 102). These positions betray a craving for objectivity in literary studies. Scholars, as Fleissner observes, increasingly turn to the cognitive sciences in an attempt to correct the interference of the critic's subjectivity with what is postulated to be "accurate" knowledge of texts. The search for method becomes a way to develop a distance from the excesses of the past decades, and thereby to disarm the "insistence on criticism as a forthrightly political act" (2017:102). Mary Thomas Crane, for example, advocates

One World The Americas Everywhere a "methodological tool kit" that might supplant the consolidated, but problematic, "practice of reading for symptoms of hidden contradictions within cultural systems" (Crane 2009: 77).

The waning of the primacy of language is intimately linked to the rejection of critique understood as symptomatic reading, but it also parallels a larger problem that bears on the status of literary criticism as a field. Toril Moi illuminates the problem. From her point of view, it would be misleading to speak, as Mary Thomas Crane does, of a "methodological took kit," as it would be misleading to speak of a method that will cure the political

6. I capitalize the word 'Theory' to indicate not only a new genre of literary criticism but also a historical moment localized in the US and in the Anglophone world thereto connected. 
and theoretical excesses of the past decades. As Moi reminds us, literary criticism is about reading, and reading is not a method. While granting that literary critics "mistake political and existential investments for methods, specific practices of reading" (2017: 179), Moi argues that the search for method distracts us from the more radical problem of our field, and that is the fact that reading is a practice. The "weak"sense of method might be the reason why some scholars lament contemporary literary critics' reliance on other disciplines-linguistics, psychology, philosophy, and so on-for theoretical grounding (Crane 2009: 67). Should this dependence on others be seen as some fundamental lack? Should the critic's dependence on the neighbor be a source of anxiety? ${ }^{7}$

If, as Moi contends, literary criticism means the practice of reading, and if the field therefore cannot be said to "have anything that we can call competing methods" (2017: 178), ${ }^{8}$ then close proximity with other disciplines may itself be constitutive of the field. Perhaps, it is precisely in this proximity that criticism can perceive itself as "living philosophy": a thought understood not so much as a philosophy (or a systematic set of rules), but in the sense of a reflection, a thought-in-the-making.

\section{SUBJECTIVITY AND THE PHYSICAL WORLD}

The craving for objectivity in literary criticism, manifest in the formerly unlikely marriages with other, distant, disciplines, goes hand in hand with a renewed interest in the physical world. Philosophers such as Levi Bryant, Nick Srnicek, and Graham Harman pair "realism" with "materialism" to indicate that the reality neglected in the former twentieth century epistemological paradigms that needs to be attended to today is the reality of the physical world.

7. In her 2006 Presidential Address, MLA President Marjorie Perloff concludes that "instead of lusting after those other disciplines that seem so exotic primarily because we don't really practice them, what we need is more theoretical, historical, and critical training in our own discipline" (qtd. in Lesjak 2013: 234).

8. Thus, when we talk of poststructuralism, feminist theory, or simply theory, we do not talk of methods per se unless, of course, we encourage our students to apply a certain theory to a text, but in so doing we would encourage them to repeat procedures leading to mechanical, standardized, production of interpretations. See Toril Moi (2017: 179). 
In their introduction to the volume The Speculative Turn (2011), they hail the birth of "a new breed of thinker" who, regardless of the discipline he or she comes from, once again asks "questions about the nature of reality independently from human thought and from humanity more generally" (3). Contributors to the volume include Bruno Latour and Isabelle Stengers, two philosophers of science who have recently exerted significant influence on Anglophone literary studies with their view that the physical world is not about the empiricism of facts but, as Stengers puts it, about "the adventure of interpretation" (2011: 372). The definition appeals to one of the affects at the basis of reading, that is to say, wonder. For Stengers, interpretation is observation guided by the capacity for accepting what we see beyond the dogmas of reason. Her view would be embraced by many literary scholars, who, in the past decades, have hoped for the potential of interpretation to subvert dominant beliefs and established schools of thought (2011: 372). ${ }^{9}$

The other influential thinker included in The Speculative Turn is Bruno Latour. He shares Stengers's views but prefers to talk about the "real world." Latour argues for the exigency of our time "to raise the question of what the real world is really like" (2005: 117). His stress on the physical world modifies inherited accounts of modernity. In his own alternative account, modernity departs from its identification with rationalism and industrialism, as it is commonly construed in literary studies. He proposes a new

One World

The Americas

Everywhere ontology of relations by updating the old debate about the "two cultures." This debate, in the late 1950s and the early 1960s, was led by figures like C. P. Snow and Aldous Huxley. Snow argued that the physical world, as an edifice erected by science, has an "intellectual depth" and a complex articulation that deserves aesthetic and critical investigation. ${ }^{10}$ Huxley exhorted to "a not too hostile symbiosis" between the scientific and literary communities,

9. To illustrate the subversive potential of observation, Stengers quotes the example of Diderot who once said to D'Alembert: "Do you see this egg? With it you can overthrow every school" (2011: 373).

10. See C. P. Snow's The Two Cultures (2012). Its central concept was originally presented as a lecture, "The Two Cultures and the Scientific Revolution" in Senate House, Cambridge, in 1959. 
wondering whether language could do justice to the physical world; he weighed the "crudeness of thought against matter, which is dynamic beyond any imaginable limit" (1963: 118). Both Snow and Huxley pointed to the problem of the literary critic who defined himself/herself against the horror of industrial modernity and the paralyzing power of science and technology. Following up on his predecessors, Latour further highlights the problematic figure of the critic. He denounces the scholars in the humanities who perceive themselves as guardians of a variety of immaterial objects: "souls, minds, interpersonal relations, the symbolic dimension, human warmth, local specificities, hermeneutics" (Latour 1993: 123; qtd. in Fleissner 2017: 103). ${ }^{11}$ He overcomes the divide between the two cultures by integrating human and non-human actors (artefacts, objects, organizations, etc.) in the same conceptual framework, where all actors indistinctly are given the same potential for agency (actor-network theory). ${ }^{12}$

Literary studies have been especially receptive to this relational ontology because it seems to open up a space of thought away from hierarchies, from sovereignty and vertical structures. ${ }^{13}$ But the success of Latour's pervasive relationality lies in the fact that the emphasis rescues the critic from what is perceived as the poststructuralist imperative of "a panoramic vision of the social order" (Felski 2015: 157), and restores to him/ her the freedom of wonder. The restitution is palpable in certain metaphors put into play by the proponents of postcritique. Felski, for example, opposes the "impassive, scrupulously judgmental"

11. In her essay "Mapping, Bridging, Quilting: Tracing the Relations between Literature and Science," which introduces the volume The Art of Discovery (2010), Margareth Hagen discusses "the cultural and historical turns, the continuities and discontinuities" that have shaped the dialogue between the literary and scientific communities over time and in different geographical areas.

12. See Bruno Latour, Reassembling the Social. An Introduction to ActorNetwork Theory (2005).

13. In Wai Chee Dimock's words, "Latour urges us to think instead about tangential processes, wayward lines of association, oblique to an existing system, pulling away from it and stretching it in unexpected ways. There is no reason why we should not work with these centrifugal forces, these "long networks" that head out-"mediators" that reopen closed cases and undo any naturalized hierarchies" (2013: 736). 
observer cultivated by thinkers like Michel Foucault (who have been insistently labeled as poststructuralist) with another kind of observer, ready "to trudge along [...], marvelling at the intricate ecologies and diverse microorganisms that lie hidden among the thick blades of grass" (157-8).

The realist attitude may offer a relief from the clutches of previously dominant logocentric paradigms of thought, with their shared belief that experience is mediated by language and that culture, conscience, power constitute and found reality. From the realist and materialist philosophers' point of view, the new type of thinker no longer relies on concepts like "text" and "discourse" (Bryant, et al. 2011: 3), but this fact may pose a problem for the literary critic. Postcritique wishes to effect a welcome transition toward more reparative ways of reading, but how might a literary critic pursue this protective task without the notion of the text? How might one think of the text in different ways? Moreover, if one considers texts as "wounded and vulnerable artifacts of history" (Felski 2016: 217), what might their wounded status and their vulnerability consist in?

\section{THE ACTUAL MODERNISM}

Even when literary studies draws on neighboring disciplines, there is no complete assimilation. Difference persists. When Felski draws on the philosophical trends that attempt to emancipate the world from human perception, the difference separating

One World The Americas Everywhere the realists from poststructuralists becomes manifest as "modernism." In literary studies, "modernism" has traditionally been construed as an aesthetic reaction to industrialized "modernity,"14 which projection has fostered "adversarial schemes that counterpose" dominant interests to "the ruptures and innovations of a marginal avant-garde" (Felski 2016: 217). Modernism, therefore, is synonymous with rupture and, undoubtedly, that has been part of its attractiveness as a field of study. Felski argues that the critical tool of rupture "has lost its last shreds of analytical purchase" (217). ${ }^{15}$ Tellingly, in the philosophical camp sympathetic

14. See Rainey and von Hallberg (2010: 471-499; 498).

15. In the same introduction to the special Latour issue New Literary History, Felski worries that the scholar should be able to speak to wider audiences 
to postcritique, there seems to be no drive toward the rejection of modernism but an interest in the re-circulation of its neglected strains. Theorists of new ontologies, like Latour and Graham Harman, re-energize the legacy of modernist thinkers like William James and Alfred North Whitehead, who have shifted into the margins of the academic attention during the heyday of poststructuralism. James and Whitehead, far from assuming that reality appears "only as the correlate of human thought" (Bryant, et al. 2011: 3), think of it exclusively in terms of relations and becoming (Shaviro 2011: 286). As a result, while literary scholars seek an alternative to modernism's worn discourse on the new (tradition vs. the avantgarde), the philosophers seem to return to the question of the new. Steven Shaviro's essay, “The Actual Volcano: Whitehead, Harman, and the Problem of Relations," seems to be an illustrative example of the re-circulation of modernism in the philosophical debate on realism. In his text, Shaviro presents James and Whitehead not as thinkers of being but as thinkers of becoming. For James and Whitehead, being thrown in(to) the world means being immersed in a bustling democracy of neighboring creatures (Shaviro 2011: 287). In the light of Shaviro's reflection, the two modernists embody an alternative line of thought that attributes value to the "hidden life of things" and stresses the importance of "conjunctive relations" among entities (Shaviro 2011: 287). With regard to Whitehead-the author, among others, of Process and Reality (1929)-Shaviro explains that the British philosopher spoke of the "really real" things that simultaneously constitute the uni-

and to "multiple constituencies" (2016: 219). This preoccupation perhaps says more about the critic brooding on his or her own performance than about critique. At some level, it does feel as a return to the kind of impasse that led intellectuals like Sontag in the 1970s to reject the then dominant narrative linking modernism to the question of the public intellectual, that is to say, to the necessity of an élite that explicates a difficult sensibility to the masses. From this perspective, the rejection of critique, because of the kind of impasse to which it leads, can already be heard in Sontag's work: "I am an adversary writer, a polemical writer. I write to support what is attacked, to attack what is acclaimed. But thereby I put myself in an emotionally uncomfortable position. I don't, secretly, hope to convince, and can't help being dismayed when my minority taste (ideas) becomes majority taste (ideas): then I want to attack again. I can't help but be in an adversary relation to my own work." (Sontag 2012: 397). 
verse and are both entities and opportunities (Shaviro 2011: 284). Because Whitehead thinks of entities in terms of "constructive functioning" (convergences, alliances) associated with "an infinite wealth" of possibilities that we can choose from (Shaviro 2011: 286), Shaviro can thrust into relief the aesthetic component of his predecessor's thought. As an example of this aesthetic component, he singles out Whitehead's notion of "patterned contrasts," a phrase that indicates differences that are reconciled and adapt to each other. Shaviro argues that Whitehead's aesthetic component proves his affinity to the twenty-first century-the present. ${ }^{16}$ The scholar argues that the modernist philosopher helps to detect the pervasive relationality of our time, which manifests itself, first and foremost, in a predominant aesthetic practice that involves "sampling, synthesizing, remixing, and cutting-and-pasting" (290). Thus, entering into a dialog with Whitehead, Shaviro can go on to raise the following questions: "How can recycling issue in creativity, and familiarity be transformed into novelty? Through what process of selection and decision is it possible to make something new out of the massive accumulation of already-existing materials?" (290). These are familiar questions; it is possible to hear in them the problem of the new in the same terms, in which Walter Benjamin posed it, that is to say, in the terms of the copy: can the copy (departing from the original) produce the new and the unexpected? ${ }^{17}$

Through Whitehead, then, Shaviro translates the problem

One World

The Americas

Everywhere of the new into the question of relationality in the contemporary world, where "all manners of cultural expression are digitally transcoded and electronically disseminated, where genetic material is freely recombined and where matter is becoming open to direct manipulation on the atomic and subatomic scales" (2011: 289). The translation returns to us the world-as-surface: there are no "hidden depths"; "nothing is hidden" (2011: 289). If we consider

16. Shaviro argues that the modernist Whitehead is closer to the twentyfirst century than his own contemporary colleagues like Graham Harman, who, following up on Whitehead, develops the concept of "allure," a generative principle of new relations among objects that exists in nuce in reality, including the inanimate sphere (Harman 2005: 244).

17. See Boris Groys (2012: 104). 
Shaviro in conjunction with the current rejection of depth (symptomatic reading) in literary studies, then both the philosophers and the literary critics would seem to agree on celebrating surfaces. In fact, Whitehead's "patterned contrasts" enable Shaviro to shift a little closer to an aesthetic view of reality that is rather familiar to the literary critic. But from the latter's point of view, this common ground in the celebration of surfaces might eclipse some difficult questions.

THE VOLCANO AND THE CROISSANT: HERMENEUTIC DISTANCE

When Shaviro discusses Whitehead's concept of real entities as real forces to be reckoned with, he offers his readers the precursor's example of the volcano. Whitehead talks of the real entity-the "volcano," and not of the different perceptions of the thing; he affirms "the actuality of the volcano" not by "isolating it from the world" or by "reducing its dynamism to a sort of sterile display," but by showing its "direct effects upon other entities" (Shaviro 2011: 288). Shaviro's point is to emphasize that things are not "just available to us," but they are "unavoidable": we "cannot expect to escape [the volcano's] eruption" (290). The above notwithstanding, the volcano, remains a strange example because it can (con)fuse the pervasive relationality of the "universe of things" (290) with the human condition haunted by subjection to necessity and fatality. The "volcano" has a way of reminding us of our human insignificance; this is why it works well as a warning against the tedious "human-centered mandate of contemporary thought" (Harman 2005: 104).

Yet, what if we try and replace the volcano with some other thing present in the universe of things? For example, a jam croissant? Say, it is an early morning, bathed in the glorious light of spring. You are sitting at a cafe, when someone, probably a woman (you hear the rustle of a long skirt), walks up to your table, wishes you a sunny "Cood morning!" and asks if you could spare some change. You consent to a compromise, offering her to get something at the coffee place. She goes in, comes out, waves a small paper bag. She has bought a croissant, "a croissant with jam," she specifies, and in reply you catch yourself saying: "So, next time I will know," and meaning it. Does 
the relationality illustrated by this anecdote confirm that nothing is hidden? Does it comfortably illustrate that everything is transcoded, translatable, without hidden depths? Perhaps the example is far-fetched; after all, the volcano and the croissant have little in common, but the volcano and the woman do: they are both facts of life. Unless one chooses the life of a hermit, encountering people and their problems and making choices while entering into relations is as unavoidable as making choices in the face of the explosion of the volcano. While the example of the volcano showcases the impact of an agent on another agent, reducing language and human thought to insignificance, this is harder to do in the case of the example of the woman in need. What happens in this setting is not as clear as it is in the case of the volcano. The mediating role taken on by the croissant only serves you to somehow "withstand the unavoidability" of the woman. Naturally, questions must arise. What drives you to pay for the croissant? A never incurred debt toward the woman who is a complete stranger? If so, could the debt ever be paid? If, for some reason, you cannot have jam croissants and experience an emotion when the stranger whom you have helped, eats them for you, what kind of a dynamics do you experience? The croissant points to a relationality of entities connected, but also withdrawn from one another, a relationality of monads-in-relation. This, of course, is nothing unique; the example illustrates an experience shared by most people, one that Toril Moi calls "human separation":

One World

The Americas

Everywhere most of us have found ourselves in "situations in which we feel powerless to know the thoughts and feelings of another human being" (2017: 206). The croissant anecdote is one of the infinite number of examples of human separation, and yet, "the unavoidability of the woman-in-distress" does not prove that human separation is a tragic condition. On the contrary: it is a promising pre-condition for knowledge.

In the activity of reading, this fundamental human separation translates into a productive gap. We might call it hermeneutic distance: engaging in the act of reading means agreeing to bridge the distance between the text and the reader. As long as we read, we are called (we decide to accept the call) to bridge a distance through language and thought. Even the realists and the new 
materialists have a notion of the task, which becomes clear when llya Prigogine and Isabelle Stengers, speaking in the name of science, consider the notion of sensitivity: "What is a being sensitive to? What can a being be modified by? What do its reactions to the world make a being capable of? Similar questions already make sense for simple 'beings' like physical-chemical systems. But how could they not be an even more pressing concern for anyone who studies living beings endowed with memory and capable of understanding and interpreting?" (Prigogine and Stengers 2014: 64). Elaine Scarry had the problem of hermeneutic distance in mind when she called for the labor of imagining others (1998: 40-62; 45). Today, Scarry's imaginative labor has been extended. Latour extends hermeneutic distance with respect to everything when he writes: "Hermeneutics is not a privilege of humans but, so to speak, a property of the world itself" (2005: 245). The scholar suggests that the problem is not to get rid of language and thought but to experiment with new ways of reading. Felski's emphasis on the affects of critique reflects the critic's deeply felt need for a shift from suspicion to reparation, or, in other words, from "interrogating, demystifying, de-familiarizing," as Anker and Felski observe in their introduction to Critique and Postcritique, to preserving and protecting. What the critic wants is exactly what Dorothea Tanning's poet wants: a "graduation" from hating the world to loving the world. The graduation is a necessary transitional stage of a larger epistemological shift, but there are also other factors instrumental to the demise of the set of gestures that have been commonly associated with critique, and that have long been considered indispensable to any serious criticism.

\section{"AGAINSTNESS" AND EURO-AMERICAN RELATIONS}

It comes as no surprise that critique is entangled with political and social factors that seem hard to ignore as they determine the limits of any critical activity. Politics and social dynamics impact both the directions of research and the production of knowledge within literary studies. One of the outcomes of this is the change of the value of literature in the space of the University, which institution has become increasingly dependent on the quantification of research. Another consequence of such an interdependency 
is the fall of the critic from his/her role as a public intellectual. Perhaps unlike in the countries in which poststructuralist thought was an expression of intellectual resistance to totalitarianism, in America today being a public intellectual requires a reorientation of philosophical positions. Should a critic adopt a deconstructive mode of reading, or act on suspicion (as the motivating affect of his or her pursuit of meaning), he or she would be seen as a destructive agent, unable to defend the value of literature and art outside the academic circles. In this climate, what formerly had been the virtue of critique, and that is, "the suspension of ordinary beliefs and commitments" (Felski 2015: 25), is now perceived as an obstacle in the adventure of interpretation.

Moreover, the rejection of what Felski dubs as "againstness" is brought about by the transformation of the fields of study that are immediately related to critique. For example, as has already been hinted, there is an intimate link between critique and modernism. Conjoined in their reliance on rupture, on adversarial temporalities that oppose any dominant culture, both modernism and critique share a common perspective. The above notwithstanding, as modernism becomes more geographically decentered, more lateral and paratactic (Friedman 2015), the objects of attachment that it had produced for the uses of criticism fade in the horizon. Among these objects of attachment are the opposition between center and margins, an adversarial, often anti-institutional, stance against

One World The Americas Everywhere power, and iconoclastic negativity. The effect of their disappearance is registered by Wai Chee Dimock in the phrase "weak theory": it may be taken to refer to the weakening of the critic's object of attachment (first and foremost, the center-margin oppositions), and the ensuing feeling of being stranded in a zone of "noncommunicability" (Dimock 2013: 751). What wanes with the modernist-theoretical objects is also the idea of the new conceived as a discontinuous sequel, with the logic of the avant-gardes also functioning as a template for the classification of critical schools. These appear, only to be superseded by the next: German Critical Theory, French Theory, Weak Theory, Italian Theory-in a continuum that entwines "aesthetic and social worth," but makes both intelligible only "in terms of a rhetoric of againstness" (Felski 2015: 17). 
Combined with all of the above, the decisive factor in the debate on postcritique is the fact that the very prefix "post," paradoxically, projects the end of the process of modernization within individual (national) cultures. In contemporary narratives about its limits, critique appears as a phase of American modernization, as a localized instance of acculturation that is made visible at its crepuscular moment. As an example, Eric Hayot's account of this evolution may be provided:

It is in the nature of idealisms to disappoint. You start out planning to change the world; you end up teaching in a university, changing one small thing or another in yourself, your students, or the curriculum, while the world goes on without you. Or you end up changing quite a lot-perhaps as one small soldier in the giant army of that used to be called lesbian and gay studies, and is now queer studies, and army that helped make possible the stunning national and international transformations in the political status of homosexual, transexual, and transgendered men and women, and in the civic recognition and legitimation of their sex and love. Or perhaps as a teacher of teachers who have rewritten high school and university curricula in the United States to include engagement with the bleak, inspiring history of ethnic struggle, or with the fight for women's rights, and with the art and the literature of those battles, a change that seems radical and huge to someone who in his American high school English classes never read a single book written by a woman, or a person of color. (2017: 282)

Only by recounting the decline of critique can one fully realize its local achievements. In the narrative above, the waning of critique (the necessity of debunking the inherited approaches to reading) generates a productive distance from the past, or, in fact, creates the narrative of a critical past. The relocation of foreign thinkers to the United States in a procession of critical schools-"the way that Foucault succeeded Derrida, Bourdieu Foucault, Badiou, Bordieu, Rancière Badiou, and so on"-effects "the Theoretical revolution in the American academy" (Hayot 2017: 287). At the same time, such a narrative makes clear that critique is an episode in EuroAmerican relations, a phase of the transatlantic modernization. And while dwelling on the prefix "post" might seem to be tantamount to "stating the obvious," one might argue that one of the reasons for the fortune of the term "postcritique" lies in its promise of a departure from that process of modernization. The new beginning that it announces affords a sense of relief. It is 
One World

The Americas

Everywhere

as if a space were finally cleared to ask about literary criticism and wonder what sort of pursuit it might be. Hayot writes: "What we know is that something has been lost, that literary criticism, today, floats adrift on an open, darkling sea, while the sailors search desperately for new compasses. Something has changed" (279). Againstness is the critic's desire (rather than a critical tenet); it traverses fields of studies and shapes them according to an intercultural (transatlantic) imperative, only to evaporate once the realization of a vaster world of "global patterns" sets in. Its "sheer scale" neutralizes "the possibilities of individual and social resistance to capitalism and violence" (283). The prefix marks the end of a phase of Euro-American two-way modernization and the exposure of the US to what Jean-Luc Nancy would call "the game of the world" (qtd. in Esposito 2016: 218).

Felski, too, observes that the demystifying posture of critique is "transmitted across the Atlantic" (Felski 2015: 76). ${ }^{18}$ Reflecting on this view, philosopher Roberto Esposito offers a different account of critique: an account afforded from the vantage point of the recent phenomenon of "Italian Theory," the narrative of whose emergence Esposito has offered to his reading public on more than one occasion. In Pensiero Vivente [Living Thought] (2010) he traces its beginnings to the success that living Italian authors attained within American academia and the popularity they enjoyed among American scholars. This phenomenon closely resembles the rise of French Theory and of Cerman theory before (earlier critical theory of the Frankfurt School and the success of its champions-Adorno, Horkheimer and Marcuse) (Esposito 2010: 3). In the context of "Cerman Philosophy, French Theory, Italian Thought," Esposito sees "Italian Theory"-a label circulated in English-as part of the movement of deterritorialization which has propelled European philosophy outside its boundaries, in a sequence of attempts "to reinvent itself along other trajectories" (Esposito 2015: 105). He focuses on a series of geographical and intellectual displacements, beginning with the great critical

18. This would be a "reworking of critique" in whch "the task of the critic is not to unmask falsehoods in order to replace them with truths but to squelch the desire for such substitutes by stressing the radically contingent and contestable nature of belief" (Felski 2015: 76). 
theorists of the Frankfurt School, and pointing to the transatlantic shift of French Theory as one of the waves in an ongoing process. Clearly, there is a difference between the two waves, and Esposito points it out: the first ensues from traumatic historical events, the second is devoid of any tragic resonance. Both waves, however, offer examples of the inventiveness and the productiveness linked to geographical displacement, which "resulted in a contamination and in a circulation of ideas that took on the traits of a veritable hegemony in a number of disciplines, from literary criticism to gender studies and postcolonial studies" (Esposito 2015: 106).

Esposito reminds us that once it crossed the Atlantic, the philosophy of Derrida, Deleuze, or Foucault "became quite other as decontextualized fragments of their thought amalgamated in a new discourse called 'theory'"' (Esposito 2015: 106). In the series of geographical-intellectual displacements, within the context of the Euro-American exchange, "Italian Theory" would constitute the third wave of theory. As such, Italian Theory continues-but also modifies-the movement, shifting the critical emphasis onto an object marginalized by the previous two. While German critical theory emphasized the social dimension and French theory the textual dimension, Italian theory emphasizes the "constitutively conflicting space of political practice" (Esposito 2015: 107). Esposito talks of "living thought," outlining critique as a larger, dynamic movement, with the result that the new discourse of theory, rather than marking the melancholia for the loss of a local transatlantic past, signals the emergence of a latent body of thought that is particularly attuned to the "dynamics of globalization and immaterial production of the postmodern" (Esposito 2010: 5). He favors the term "thought" to "theory" because it can deterritorialize what is labelled "Italian Theory" into a space of reflection that is far from national, comprising Dante and Machiavelli-but also Spinoza, Nietzsche and Foucault. In Esposito's narrative, the adjectives of nationality performatively call the audiences' attention to the Anglo-American incorporation of European philosophies in linear chunks of continental traditions: post-WW II Cerman Critical Theory first, poststructuralist French Theory later, and now-Italian Theory. The philosopher, however, seems to invite his readers to conceive of critique in terms wider 
than those emerging solely as a result of the increased visibility of "national" differences in the transatlantic context. His discussion departs from the "national labels": the philosopher proposes a line of reflection that offers an alternative to the hermeneutics of suspicion, and that evolves at an eccentric pace, simultaneously preceding and exceeding "analytic, hermeneutic and deconstructive philosophies" (Esposito 2016: 161). Re-introducing theory into the now reoriented academic discourse, Esposito helps to revise the familiar account of critique in the context of geographicalintellectual displacements that admit of a different "affirmative tonality" (Esposito 2015: 110). He emphasizes the inclusiveness of critique, which no longer emerges in an antagonistic relation to global patterns and their overwhelming scales, but as coterminous with these changes.

\section{IN LIEU OF CONCLUSIONS: THE PLANE OF COEVALNESS}

Of course, one should not forget that Esposito is, first and foremost, a political philosopher, a critic of political theology (Esposito 2015: 104-110). Transferring his terms from philosophy to the literary realm implies the risk of conceptual deracination and estrangement. At the same time, his description of theory reminds us that the contact between philosophy and literature (understood both in terms of the texts they produce and in terms of the critical discourse they generate) is fundamental to critique, especially when seen from the vantage point of the experience of US theory.

One World The Americas Everywhere As mentioned above, Esposito speaks of the decontextualization of non-American thinkers, whose work is then assimilated in multiple disciplines, including literary studies, owing to the dissemination that only US English may afford today.

Esposito's account shares postcritique's disaffection for the "vast saga of radical rupture" that the conceptualization of the new has required (Harman 2009: 60). Like Felski, he departs from the model of rupture. Analysizing this model within European thought, he finds that the production of the new has been made possible by "the construction of a threshold-whether anthropological, epistemological, or institutional-which shelters from something primordial and constitutive, that cannot be governed by reason but instead threatens reason" (Esposito 2010: 24). He calls this "something 
primordial and constitutive," which is deferred, but always returns aggressively, a "pre-reflexive magmatic substance" [sostanza magmatica pre-riflessiva]. It is sometimes identified with an "anthropic margin that is still too contiguous with the animal dimension" and at other times, with the language of magic and myth (24). The magmatic pre-reflexive substance is constituted as "the origin" that subjects thinkers to its spectral returns. Only if one succeeds in fending off these returns, can he or she seek new beginnings. As an alternative to the "magmatic" account, Esposito proposes another environment of thought calling forth the image of a plane of coevalness. This is a benevolent (and beneficial) plane where "the origin is made available as a resource rather than something to be subjected to as if to a spectral return" (25).

Looking at the contextual map of loci in which the prefix "post" occurs in the contemporary "post-critical" debate, which this article aspired to sketch out, it seems clear that the epistemic transformation postulated, or wished for, by the proponents of the "post," requires that the critical debate move to the plane which may only emerge from the realization of the possibility of "'another' modernity" (Esposito 2010: 23), a modernity that departs from accounts based on the linear temporality of progress. In such accounts, a presupposed unevenness of cultures (or gaps between cultures) overshadows the multiple locations of ideas and the effects of their circulation. The plane of coevalness differs from the surfaces of new materialism and the radical relationality of new realism, and extends beyond Latour's bustling network of actors. Like them, it moves beyond rupture, but, unlike them, it looks back, especially through feminism and psychoanalysis, to the experience of speech and to the notion of life understood as always incomplete, always in tension with its context, and always at odds with history. 
WORK CITED

Anker, Elizabeth S. and Rita Felski. Introduction. Critique and Postcritique. Duke UP, 2017. pp. 1-28.

Arendt, Hannah. The Human Condition. The U of Chicago P, 1998.

Bertens, Hans. Literary Theory: The Basics. Routledge, 2007.

Bryant, Levi, et al. "Towards a Speculative Philosophy." The Speculative Turn: Continental Materialism and Realism, edited by Levi Bryant, et al. re.press, 2011, pp. 1-18.

Collini, Stefan. "The Identity of Intellectual History." A Companion to Intellectual History, edited by Richard Whatmore and Brian Young. John Wiley \& Sons, Incorporated, 2015. http://ebookcentral.proquest.com/lib/luc/detail.action?doclD=4529146. Accessed 30 Apr. 2020.

Crane, Mary Thomas, "Surface, Depth, and the Spatial Imaginary: A Cognitive Reading of The Political Unconscious." Representations, vol. 108, no. 1, 2009, pp. 76-97.

Dillet, Benoît ."What is Poststructuralism?" Political Studies Review, vol. 15, no. 4, 2017, pp. 516-527.

Dimock, Wai Chee. "Weak Theory: Henry James, Colm Tóibín, and W. B. Yeats," Critical Inquiry, vol. 39, no. 4, 2013, pp. 732-753.

Esposito, Roberto. "German Philosophy, French Theory, Italian Thought." Translated by Mena Mitrano. "Forum: American Studies and Italian Theory." RSA Journal, no 26, 2015, pp. 104-114.

One World The Americas Everywhere
------. Pensiero Vivente: Origine e attualità della filosofia italiana. Einaudi, 2010.

------. Da Fuori: Una Filosofia per l'Europa. Einaudi, 2016.

------. Pensiero Istituente: Tre Paradigmi di Ontologia Politica. Einaudi, 2020.

Felski, Rita. "Introduction," Re-composing the Humanities-with Bruno Latour, New Literary History, vol. 47, no. 2-3, 2016, pp. 215-229.

------. The Limits of Critique. The $U$ of Chicago P, 2015

Fleissner, Jennifer. "Romancing the Real: Bruno Latour, Ian McEwan, and Postcritical Monism." Critique and Postcritique, edited by Elizabeth S. Anker and Rita Felski. Duke UP, 2017, pp. 99-126. 
Friedman, Susan Stanford "Musing Modernist Studies." Modernism/ Modernity, vol. 17, no. 3, 2010, pp. 471-499.

------. Planetary Modernisms: Provocations on Modernity Across Time. Columbia UP, 2015.

Groys, Boris. Introduction to Antiphilosophy. Translated by David Fernbach. Verso, 2012.

Hagen, Margareth. "Mapping, Bridging, Quilting: Tracing the Relations between Literature and Science." The Art of Discovery: Encounters in Literature and Science, edited by Margareth Hagen, et al. Aarhus UP, 2010, pp. 9-28.

Harman, Graham. Guerrilla Metaphysics: Phenomenology and the Carpentry of Things. Open Court, 2005.

------. Prince of Networks: Bruno Latour and Metaphysics. re.press, 2009.

Hayot, Eric. "Then and Now." Critique and Postcritique, edited by Elizabeth S. Anker and Rita Felski. Duke UP, 2017, pp. 279-295.

Huxley, Aldous. Literature and Science. Harper \& Row, 1963.

Lacan, Jacques. "Discorso di Roma." Altri scritti, edited by Antonio di Ciaccia. Einaudi, 2013, pp. 133-164.

------. "The Function and Field of Language in Psychoanalysis," Écrits, edited by Alan Sheridan. W. W. Norton \& Company, 1977, pp. 30-113.

Latour, Bruno. We Have Never Been Modern. Translated by Catharine Porter. Harvard UP, 1993.

------. Reassembling the Social: An Introduction to Actor-Network Theory. Oxford UP, 2005.

Lesjak, Carolyn. "Reading Dialectically." In Literary Materialisms, edited by Mathias Nilges and Emilio Sauri. Palgrave Macmillan, 2013. pp. 17-47.

Love, Heather. "Close but Not Deep: Literary Ethics and the Descriptive Turn." New Sociologies of Literature. Special issue of New Literary History, vol. 41, no. 2, 2010, pp. 371-391

------. "Close Reading and Thin Description." Public Culture, vol. 25, no. 3, 2013, pp. 401-434.

Marcus, Sharon and Stephen Best, eds. Description Across Disciplines. Special Issue. Representations, vol. 135, no. 1, 2016. 
One World The Americas

Everywhere

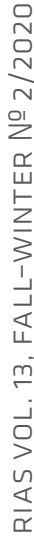

------. "Surface Reading: An Introduction." Representations, vol. 108, no. 1, 2009, pp. 1-21.

Marcus, Sharon, Heather Love and Stephen Best, eds. Description Across Disciplines. Special Issue. Representations, vol. 135, no. 1, 2016.

Marcus, Sharon. Between Women: Friendship, Desire, and Marriage in Victorian England. Princeton UP, 2007.

Moi, Toril. Revolution of the Ordinary. Literary Studies after Wittgenstein, Austin, and Cavell. U of Chicago P, 2017.

Prigogine, Ilya and Isabelle Stengers. Tra l'eternità e il tempo. Translated by Carlo Tatasciore. Bollati Boringhieri, 2014.

Rainey, Lawrence and Robert von Hallberg, "Introduction," Modernism/ Modernity, vol. 1, no. 1, 1994, pp. 1-3.

Scarry, Elaine. The Difficulty of Imagining Other Persons. In The Handbook of Interethnic Coexistence, edited by E. Weiner. Continuum, 1998, pp. 40-62.

Shaviro, Steven. "The Actual Volcano: Whitehead, Harman, and the Problem of Relations." The Speculative Turn: Continental Materialism and Realism, edited by Levi Bryant, et al. re.press, 2011. 279-290.

Snow, C. P. The Two Cultures. Cambridge UP, 2012.

Sontag, Susan. As Consciousness is Harnessed to Flesh: Journals o Notebooks 1964-1980, edited by David Rieff. Farrar, Straus, and Giroux, 2012.

Stengers, Isabelle. "Wondering about Materialism." The Speculative Turn: Continental Materialism and Realism, edited by Levi Bryant, et al. re.press, 2011, pp. 368-380.

Tanning, Dorothea. "Graduation." A Table of Content: Poems, Graywolf Press, 2004, p. 20.

Williams, James. Understanding Poststructuralism. Taylor \& Francis Group, 2014. http://ebookcentral.proquest.com/lib/luc/ detail.action?docID=1900170. Accessed 05 Jan. 2020. 